\title{
OS TRAÇADOS HISTÓRICOS DAS RUAS DE LAZER PRESENTES NA "ABERTURA" DA AVENIDA PAULISTA
}

\author{
Jordania de Oliveira Eugenio ${ }^{1}$
}

\begin{abstract}
Resumo: O presente artigo busca apresentar de que forma os traçados históricos das Ruas de Lazer existentes em São Paulo desde 1976, compuseram a mobilização acerca da abertura da Avenida Paulista para os pedestres a partir de 2015. Para tanto, utilizou-se da revisão bibliográfica e análise de dados secundários (sites de notícias e blogs da cidade de São Paulo) com vistas a compreender como ocorreu tal processo. De forma preliminar, verificou-se que a implantação do Programa Ruas Abertas na Paulista foi cercada por embates e disputas, sendo o seu uso para o lazer um dos principais argumentos dos grupos favoráveis à abertura. Além disso, este estudo possibilitou a identificação de similaridades e contrariedades entre as Ruas de Lazer que se difundiram em São Paulo a partir de 1976, e o uso da Avenida Paulista após sua "abertura" em 2015. Por último, o exercício da cidadania, por meio da apropriação das ruas pelos próprios cidadãos, parece ocupar centralidade - ainda que indiretamente - no processo de ressignificação da Avenida Paulista.
\end{abstract}

Palavras-chave: Avenida Paulista; Ruas de Lazer; Paulista Aberta; São Paulo; Brasil.

\section{LAS MARCAS HISTÓRICAS DE LAS CALLES DEL OCIO PRESENTES EN LA “APERTURA" DE AVENIDA PAULISTA}

Resumen: Este artículo busca presentar cómo los recorridos históricos de las Calles del Ocio que existen en São Paulo desde 1976, componen la movilización sobre la apertura de la Avenida Paulista para peatones a partir de 2015. Para ello se utilizó la revisión y análisis bibliográfico datos secundarios (sitios de noticias y blogs de la ciudad de São Paulo) para comprender cómo se desarrolló este proceso. De manera preliminar, se encontró que la implementación del Programa Calles Abiertas en Paulista estuvo rodeada de enfrentamientos y disputas, siendo su uso para el esparcimiento uno de los principales argumentos de los grupos a favor de la apertura. Además, este estudio permitió identificar similitudes y retrocesos entre las Calles de Ocio que se extendieron en São Paulo desde 1976, y el uso de la Avenida Paulista luego de su "apertura" en 2015. Finalmente, el ejercicio de la ciudadanía, a través de la apropiación de las calles por parte de los propios ciudadanos, parece ocupar una posición central -aunque indirecta- en el proceso de replanteamiento de la Avenida Paulista.

Palabras clave: Avenida Paulista; Calles de ocio; Abierto Paulista; San Pablo; Brasil.

${ }^{1}$ Doutoranda no Programa de Pós Graduação Interdisciplinar em Estudos do Lazer da Universidade Federal de Minas Gerais (UFMG). E-mail: jordaniaeugenio@ufmg.br.ORCID: http://orcid.org/0000-0001-5799-9730. 


\title{
THE HISTORICAL MARKS OF THE LEISURE STREETS PRESENT AT THE “OPENING" OF AVENIDA PAULISTA
}

\begin{abstract}
This article seeks to present how the historical routes of the Leisure Streets that exist in São Paulo since 1976, make up the mobilization for the opening of Avenida Paulista for pedestrians as of 2015. For this, the bibliographic review and analysis of secondary data was used (news sites and blogs of the city of São Paulo) to understand how this process developed. In a preliminary way, it was found that the implementation of the Open Streets Program in Paulista was surrounded by confrontations and disputes, being its use for recreation one of the main arguments of the groups in favor of opening up. In addition, this study made it possible to identify similarities and setbacks between the Leisure Streets that spread in São Paulo since 1976, and the use of Avenida Paulista after its "opening" in 2015. Finally, the exercise of citizenship, through the appropriation of the streets by the citizens themselves seems to occupy a central position - albeit indirect - in the process of rethinking Avenida Paulista.
\end{abstract}

Keywords: Paulista Avenue; Leisure streets; Open Paulista; Saint Paul; Brazil.

\section{Introdução}

A abertura da Avenida Paulista para pedestres na cidade de São Paulo ocorreu de forma oficial em junho de 2016, por meio do decreto municipal no 57.086 que definiu premissas para o funcionamento do Programa Ruas Abertas, ao qual a abertura da Avenida Paulista é vinculada. Antes do decreto assinado pelo então Prefeito da capital paulista Fernando Haddad, no entanto, houveram eventos testes em 2015, quando, após ampla mobilização de moradores paulistanos, coletivos e ONGs a Prefeitura concordou em interromper o tráfego de veículos (de 10:00 às 18:00 horas) em domingos e feriados pré-determinados (para os testes), possibilitando que os pedestres utilizassem a Paulista como espaço de lazer e convivência (PASSARELLI, 2018; RETTE e BEZERRA, 2019).

Em 2020, contabilizando o período de teste, a Paulista Aberta completou cinco anos de existência, sobrevivendo à troca de gestão da Prefeitura de São Paulo em 2017, e, se popularizando como símbolo da participação dos cidadãos no âmbito das políticas públicas municipais, uma vez que, todo o processo de reivindicação e construção do Programa Ruas Abertas - que inclui a Avenida Paulista - partiu da população, alcançando, após insistência, a visibilidade do poder público (LABMOB, 2018).

Atualmente, segundo relatório de 2018, desenvolvido pelo Laboratório de Mobilidade Sustentável (LABMOB - UFRJ) em parceria com o Instituto de Políticas de Transporte e Desenvolvimento (ITDP - Brasil), e com as organizações "Bike Anjo" e "Corrida Amiga", a cada cinco minutos, em média, 950 pessoas e 70 ciclistas passam pela Avenida Paulista aos domingos e/ou feriados nos quais a mesma encontra-se "aberta". Totalizando uma estimativa 
de 102 mil pessoas por domingo/feriado, número que ultrapassa o recorde de 100 mil pessoas que estiveram na Paulista durante um domingo do ano 2016, quando as Ruas Abertas foram oficializadas (LEME, 2017; PASSARELLI, 2018).

Nessa época do embate público sobre a oficialização das Ruas Abertas em São Paulo entre os anos de 2015 e 2016 - a centralidade dos argumentos dos grupos que eram a favor do programa, estava em torno, sobremaneira, da reivindicação das ruas como espaço público de lazer (São Paulo São, 2018). O que remete ao processo que em 1976, motivou a criação da primeira Rua de Lazer vinculada à Prefeitura de São Paulo. Isso porque, a mesma nasceu do desejo e insistência da paulistana Dirce Vieria, moradora da Zona Leste de São Paulo que, conseguiu junto a essa Prefeitura, após dois anos de negociação, o direito de interditar a rua de sua residência (Manoel Faria Inojosa, em São Miguel Paulista) aos domingos e feriado para que as crianças pudessem brincar naquele espaço (SÁ, GARCIA e ANDRADE, 2017).

A iniciativa da primeira Rua de Lazer liderada por Dirce Vieira, logo se espalhou, transformando-se em demanda de outros cidadãos que, representados pelas Associações de Moradores de seus bairros, também solicitaram a interdição de suas ruas (SÁ, GARCIA e ANDRADE, 2017), dando origem em 1977, ao Programa Municipal denominado Ruas de Lazer. Tal programa, desde sua criação é vinculado à Secretaria Municipal de Esportes, atualmente denominada Secretaria Municipal de Esportes, Lazer e Recreação (SEME).

Com mais de 40 anos de existência, o Programa Ruas de Lazer segue em vigor, havendo cadastradas, aproximadamente, mil ruas em todo o município de São Paulo, sendo as regiões mais periféricas da cidade os locais onde há mais ruas vinculadas ao Programa (SÁ, GARCIA e ANDRADE, 2017). Entretanto, segundo levantamento da Secretaria de Esporte, Lazer e Recreação da Prefeitura de São Paulo, boa parte das ruas cadastradas não estão funcionando corretamente, sendo seu uso destinado apenas, por exemplo, para a interdição do tráfego de veículos aos domingos e feriados, ou para bares e outros estabelecimentos comerciais espalharem suas mesas na extensão das ruas (PENINA, 2020). O que vai de encontro ao objetivo do Programa Ruas de Lazer, que em sua gênese trás a ideia de que a via seja utilizada e ocupada pelos moradores do bairro para realização e desfrute de atividades culturais, de lazer e recreação, e não para fins comerciais, ou interrupção do tráfego de veículos sem motivo aparente.

A partir das circunstâncias iniciais brevemente apresentadas, percebe-se que os Programas Ruas de Lazer e Ruas Abertas possuem similaridades, principalmente no que diz respeito ao uso da rua como espaço público de lazer. Nesse sentindo, reconhecendo a grande concentração de visitantes na Avenida Paulista desde sua abertura, unida ao o poder simbólico 
desta via que, segundo Passarelli (2018) parece ter ofuscado o Programa Ruas Abertas como um todo, o presente estudo pretende apresentar de que forma os traçados históricos das Ruas de Lazer existentes em São Paulo desde 1976, compuseram a mobilização acerca da Paulista Aberta? Além disso, serão destacadas as semelhanças e diferenças entre os programas, priorizando compreender as novas formas de apropriação da Avenida Paulistas por parte dos cidadãos.

Com vistas a alcançar o objetivo proposto nesta pesquisa, optou-se pela revisão bibliográfica e análise de dados secundários de sites de notícias da cidade de São Paulo. Por se tratar de um estudo preliminar, neste primeiro momento lançamos mão da revisão bibliográfica de trabalhos científicos extraídos por meio da base de dados online Google Scholar, na qual foram utilizados os seguintes descritores (buscados nos títulos): "Ruas de Lazer", "São Paulo" e "Avenida Paulista" e, posteriormente: "Avenida Paulista" e "Paulista Aberta".

A coleta dos trabalhos ocorreu em outubro de 2020, sem recorte temporal delimitado e, optando apenas pela análise de estudos em português. Para a seleção dos trabalhos, primeiramente efetuou-se à leitura dos títulos e resumos dos mesmos, sendo excluídos aqueles não condizentes com o objetivo deste artigo. Ao final, utilizou-se para esta revisão 12 artigos científicos (Revista Educação Física, 2003; MUNHOZ, 2004; COSTA e SAMPAIO, 2015; BASTOS e MELLO, 2017a; BASTOS e MELLO, 2017b; SÁ, GARCIA e ANDRADE, 2017; CORDEIRO, MELLO e BASTOS, 2019; FURTADO e CASTRO, 2019; RETT e BEZERRA, 2019; ROSA e FERREIRA, 2019; PEREIRA, RETT e BEZERRA, 2020; PIMENTEL e CARRANZA, 2020), 02 dissertações (OLIVEIRA, 1998; GONÇALVES, 2010), 01 tese (MACHADO, 2014) e o Relatório de Avaliação de impacto da Paulista Aberta (LABMOB, 2018).

Ademais, como já apontado, a presente pesquisa também incluiu buscas em sites de notícias da cidade de São Paulo (O Estado de São Paulo; Cidade Ativa; Nossa São Paulo; 32xSP; São Paulo São; Veja São Paulo; 360 Meridianos; Caos Planejado, Minha Sampa ), visando extrair tanto informações acerca do processo de abertura da Paulista em 2016, como dados e elementos que compõe as discussões atuais sobre a Paulista Aberta.

$\mathrm{O}$ artigo está divido em três aparatos, sendo o primeiro dedicado ao apontamento dos traçados históricos das Ruas de Lazer em São Paulo e, o segundo destinado a discussão acerca do uso da Paulista Aberta no presente, onde se reconhece similaridades e diferenças do Programa Ruas de Lazer. Por último, são descritas algumas considerações sobre as primeiras impressões identificadas nesta pesquisa, vislumbrando novas questões para estudos futuros. 


\section{Os traçados históricos das Ruas de Lazer}

As Ruas de Lazer da cidade de São Paulo, como já introduzido, surgiram inicialmente, em 1976, após insistência da moradora da Zona Leste paulistana, Dirce Vieira que solicitou o fechamento da rua de sua residência aos domingos e feriados para que as crianças pudessem brincar (SÁ, GARCIA e ANDRADE, 2017). Com a autorização da Prefeitura de São Paulo outros moradores também demandaram o fechamento de suas ruas a exemplo do que vinha ocorrendo na Zona Leste (SÁ, GARCIA e ANDRADE, 2017), ocasionando já no ano seguinte (1997), a existência de 80 novas Ruas de Lazer no município de São Paulo (CORDEIRO, MELLO e BASTOS, 2019).

Dessa forma, de acordo com essa crescente demanda pelas interdições de diferentes ruas, em 1977, a Prefeitura Municipal de São Paulo inaugurou o Programa Ruas de Lazer, inspirado nas chamadas Ruas de Recreio presentes na cidade do Rio de Janeiro desde 1957 (SÁ, GARCIA e ANDRADE, 2017). As Ruas de Recreio da capital carioca, idealizadas pelo professor de Educação Física Alfredo Colombo, consistia no oferecimento orientado de atividades recreativas às crianças (ROSA e FERREIRA, 2019) em algumas ruas da cidade que, tinham o tráfego de veículos interrompidos, dando lugar às redes de vôlei, mesas de xadrez e damas, plintos, colchões, cordas para jogar cabo-de-guerra e etc. (Revista Educação Física, 2003). A receptividade das Ruas de Recreio foi tamanha que, além da ideia ter sido disseminada para outros Estados brasileiros, no verão de 1958, criou-se no Rio de Janeiro a "Praia de Recreio", na qual professores orientavam atividades físicas na praia do Leblon em dias específicos e de acordo com faixas etárias indicadas para as respectivas atividades (Revista Educação Física, 2003).

Ainda em 1958, a Divisão de Educação Física do Ministério da Educação e Cultura, instituiu pela Portaria Ministerial $\mathrm{n}^{\mathrm{0}} 3$, de 06 de janeiro desse mesmo ano a Campanha de Difusão das Ruas de Recreio que, deveria acontecer em todo o país com:

[...] o intuito de divertir e relaxar os participantes e privilegiava, para isso, as atividades físico-esportivas, visto que o contexto histórico da época apontava para uma forte associação entre aquele conteúdo, a recuperação da força de trabalho do operariado e a manutenção da saúde, considerada primordial para o desenvolvimento industrial de uma nação. As atividades, controladas por monitores quanto ao uso do tempo, do local e dos equipamentos utilizados, eram planejadas previamente, com base em um modelo único adotado para todas as Ruas de Recreio realizadas pelo órgão promotor, ou seja, não havia na época a preocupação de considerar as particularidades regionais, tampouco de inserir as comunidades no processo organizacional do evento - os participantes se restringiam à vivência das atividades oferecidas (MUNHOZ, 2004, p 2003). 
Nessa direção, embora as Ruas de Recreio sejam consideradas percursoras das Ruas de Lazer, nota-se que as últimas, em sua gênese, partem do desejo dos cidadãos até à chancela do poder público municipal e, não o contrário (como nas Ruas de Recreio), onde o órgão de governança propõe e executa quaisquer iniciativas sem a participação e/ou desejo dos cidadãos.

No caso do Programa Ruas de Lazer de São Paulo, por exemplo, ainda que na atualidade seja a Prefeitura quem concede a autorização para uma via se tornar Rua de Lazer, tal processo só é aberto após solicitação assinada por $80 \%$ dos moradores da rua que pleiteia a chancela do Programa $^{2}$ (COSTA e SAMPAIO, 2015; SÁ, GARCIA e ANDRADE, 2017; CORDEIRO, MELLO e BASTOS, 2019). Além disso, desde a criação das Ruas de Lazer, outro pré-requisito para sua autorização de funcionamento é a existência de um conselho formado por moradores da rua que, será responsável pelo fechamento, coordenação e planejamento das atividades junto a Secretaria Municipal de Esportes, Lazer e Recreação (SEME) (MEKARI, 2014).

As atividades oferecidas nas Ruas de Lazer variaram com o passar dos anos. Se no início do Programa a SEME disponibilizava e financiava para as atividades apenas travas para partidas de futebol, redes para prática de vôlei, jogos de tabuleiro, pinturas com guache e colagens (São Paulo São, 2018), com o passar dos anos, as Ruas de Lazer ganharam apoio de empresas privadas, instituições de terceiro setor e empresas consideradas organizações mistas, como o Serviço Social do Comércio (SESC) (MUNHOZ, 2004).

Com esses novos atores inseridos no apoio às Ruas de Lazer, as mesmas receberam outros contornos, contando, segundo Munhoz (2004) com: brinquedos infláveis, cama elástica, apresentações culturais, água, lanche e som. O que, para a autora culminou nas chamadas "ações integradas" com colaboradores diversos que reuniam,

[...] além das atividades de lazer, outros serviços de diferentes naturezas, como cortes de cabelo, stands de confecção de documentos de identidade ou carteiras de trabalho, distribuição de mudas de plantas, medição de pressão, etc. (MUNHOZ, 2004, p.204).

Na contemporaneidade, decorridas quatro décadas da existência das Ruas de Lazer em São Paulo, o Programa mostrou-se enfraquecido (CORDEIRO, MELLO e BASTOS, 2019; COSTA e SAMPAIO, 2015) e, após apuração da SEME de 2014, constatou-se que em 70\% das 1058 ruas cadastradas o tráfego de veículos era interrompido, mas na via não ocorriam atividades de lazer (PENINA, 2020), descaracterizando o intuito do fechamento das mesmas.

\footnotetext{
${ }^{2}$ A responsabilidade das Ruas de Lazer em São Paulo no presente é da Secretaria Municipal de Esportes, Lazer e Recreação (SEME) em parceria com a Companhia de Engenharia de Tráfego (CET).
} 
Um dos motivos para esse enfraquecimento parece ter relação com a baixa participação dos moradores da rua nas atividades, sendo o dia de lazer interpretado por alguns como "obrigação de divertimento" (São Paulo São, 2018).

Costa e Sampaio (2015) ainda apontaram que a falta de manutenção do Programa pela SEME, unido a mudanças de governos e a desmotivação dos conselhos formados por moradores das ruas onde ocorriam as atividades, contribuíram para a descontinuidade das Ruas de Lazer. Fato corroborado na pesquisa de Stoppa et al. (2011) que, indicou que as ruas onde o Programa continuava obtendo sucesso mesmo após diferentes mudanças, eram aquelas nas quais os moradores permaneciam envolvidos e motivados. Além dessas questões, em 2017, a Secretaria Municipal de Esportes, Lazer e Recreação afirmou ser recorrente a denúncia sobre algumas vias das Ruas de Lazer terem se tornado espaço para realização de "pancadões" 3 e outras festas, o que ocasionava conflitos entre os moradores locais (LOBATO, 2017) e o pedido para que a rua deixasse de integrar o Programa.

Dessa forma, durante a gestão do prefeito Fernando Haddad em 2013, o Programa Ruas de Lazer passou por um processo de revisão por meio do Decreto 55.684 de 12 de novembro de 2014 que, diminuiu o horário de funcionamento do Programa e, impediu/suspendeu as Ruas de Lazer em logradouros onde houvesse:

[...] templos de qualquer culto, hospitais, prontos-socorros, velórios, cemitérios, estacionamentos coletivos, linhas regulares de ônibus, pontos de táxi, feiras-livres, bares, lanchonetes, estabelecimentos de alimentação de qualquer natureza ou qualquer outro tipo de comércio (SÃO PAULO, 2014).

Além disso, no mesmo ano em que Haddad assinou o novo decreto a respeito das Ruas de Lazer, os primeiros diálogos acerca do melhoramento da segurança viária a partir de novos conceitos sobre mobilidade urbana se iniciaram no município de São Paulo (CORDEIRO, MELLO e BASTOS, 2019). Contexto no qual no final de 2014, coletivos representados pelas organizações "Minha Sampa" e "SampaPé”, solicitaram o fechamento da Avenida Paulista para o tráfego de veículo e a destinação da via para uso exclusivo dos pedestres e ciclistas (PEREIRA, RETT e BEZERRA, 2020). Tal mobilização, após eventos testes, estruturou a criação do Programa Ruas Abertas do qual a Avenida Paulista faz parte. Faz-se necessário salientar, entretanto, que o Programa Ruas Abertas não exclui o Programa Ruas de Lazer, estando ambos ativos na cidade de São Paulo atualmente.

\footnotetext{
${ }^{3}$ Festa/Baile funk aberto ao público que acontece nas ruas e aglomera grande número de pessoas.
} 


\section{A abertura da Paulista para além do lazer}

O Programa Ruas Abertas foi oficializado em 29 de dezembro de 2016, por meio da Lei Municipal No 16.607 que, abrangeu 32 subprefeituras da cidade de São Paulo tendo como principal objetivo a interrupção do tráfego de veículos e a abertura exclusivamente para pedestres aos domingos e feriados em vias autorizadas (PEREIRA, RETT e BEZERRA, 2020; RETT e BEZERRA, 2019; FURTADO e CASTRO, 2019). Uma dessas vias e, em certo ponto, a protagonista do Programa é a Avenida Paulista, localizada em uma das regiões mais elevadas da cidade.

Historicamente a Avenida Paulista passou por diferentes transformações, assumindo funcionalidades diversas conforme o passar dos anos e, de acordo com as características das décadas. Inaugurada e loteada em 1890, por iniciativa e recursos do engenheiro e empreendedor uruguaio Joaquim Eugênio de Lima, inicialmente a via abrigou casarões da elite cafeeira paulista, servindo também de passagem para carros de boi (MACHADO, 2014; FURTADO e CASTRO, 2019). O nome da Avenida Paulista foi escolhido também por Joaquim Eugênio de Lima que, ao registrá-la como "Paulista" desejou homenagear os próprios paulistas. Fato que, segundo Machado (2014), marcou por décadas essa Avenida como território no qual os habitantes se sentem na parte "mais paulistana" da cidade de São Paulo.

Nos anos seguintes à sua inauguração a via foi se consolidando como logradouro da elite cafeeira e outros e imigrantes ricos (MACHADO, 2014; BASTOS e MELLO, 2017b), sendo que já em 1900, a rua abrigava 50 casarões planejados por arquitetos estrangeiros a pedido das famílias abastadas que desejavam residir no recém Boulevard ${ }^{4}$ da cidade de São Paulo (MACHADO, 2014). E, mesmo que a Paulista tenha se consolidado no início como uma via residencial, não demorou muito para que a mesma atraísse outros interesses que atendessem à população residente no local. Exemplo disso é que em 1906 foi construído na via o Hospital Santa Catarina, em 1919 a Escola Estadual Rodrigues Alves e 1953 o Parque Trianon, destinado às atividades de lazer (MACHADO, 2014).

O formato linear da Avenida Paulista com calçadas e pistas amplas, além do fato da via ser a primeira a receber asfalto na cidade de São Paulo, favoreceu a realização de eventos públicos (como corrida de automóveis e desfiles de carnaval) no local que, segundo Machado (2014) demonstrou a "aptidão" da Avenida em receber grandes aglomerações desde sua inauguração. Perspectiva que parece ser ratificada ao longo dos 126 anos de existência da

\footnotetext{
${ }^{4}$ Termo francês usado para denominar uma via com amplitude e mais de uma pista.
} 
Paulista, visto que, a mesma foi e, ainda é utilizada na cidade de São Paulo como palco para manifestações, protestos, eventos e dias dedicados ao lazer (BASTOS e MELLO, 2017; CORDEIRO, MELLO e BASTOS, 2019).

Além disso, a configuração arquitetônica e funcional mais atual da Avenida Paulista, inicia-se na década de 1940, quando os casarões da via, ocupados pela elite do café e outros ricos paulistanos, começaram a perder espaço em decorrência da crise ocasionada pela queda da bolsa de Nova York em 1929, gerando a chamada verticalização da Paulista (OLIVEIRA, 1998; MACHADO, 2014; BASTOS e MELLO, 2017b). Esse processo, no qual as mansões foram vendidas e demolidas, dando lugar a prédios residenciais e comerciais, ajudou na construção da nova imagem da Avenida Paulista que se tornou símbolo do desenvolvimento e prosperidade da cidade de São Paulo (OLIVERIA, 1998).

Nessa direção, no inicio de 1970, a Avenida passa por uma mudança advinda do Projeto Nova Paulista, que previa o rebaixamento das atuais pistas de veículos por toda a extensão da rua, liberando espaço para a implantação de um Boulevard ajardinado, voltado aos pedestres (BASTOS e MELLO, 2017b). Tal projeto contribuiu para que o mercado imobiliário se voltasse para Paulista, gerando a demolição de sessenta mansões (algumas às escuras, antes de serem tombadas) e inúmeras árvores que deram lugar a mais prédios comerciais (GONÇALVES, 2010; BASTOS e MELLO, 2017). Como consequência dos novos contornos oriundos do Projeto Nova Paulista,

[...] a avenida sofre uma avassaladora expansão imobiliária e, em consonância a esse período, passam a se instalar ao longo de sua via, sedes de importantes bancos, empresas multinacionais, firmas e instituições de grande poder capital (GONÇALVES, 2010, p.130).

Ainda para Gonçalves (2010), essa mudança aponta o poder de adaptação às novas ordens de escala global e diretrizes urbanas mundiais que a Avenida Paulista parece ter, sendo capaz de transformar suas funcionalidades ao longo dos anos. Dessa maneira, para Bastos e Melo (2017a) ao adaptar-se às distintas transformações, a Paulista opera como uma espécie de vitrine das mudanças que acontecem na cidade de São Paulo como um todo. A saber, os próprios diálogos que antecederam o surgimento da Paulista Aberta em 2016, estavam em sintonia com o que vinha acontecendo em outros locais do mundo como em Bogotá e em Nova York (SABINO e PAIM, 2020), no que diz respeito aos processos de urbanização e mobilidade (CORDEIRO, MELLO e BASTOS, 2019).

A partir dessa perspectiva, embora a Avenida Paulista já tivesse sido fechada para veículos em outras ocasiões, como durante o Projeto "Domingo na Paulista", desenvolvido na 
gestão da Prefeita Marta Suplicy (2001-2005) que tinha o intuito de destinar a via ao lazer dos cidadãos nos dias de domingo (NOSSA SÃO PAULO, 2015); o encadeamento que marcou a abertura da Paulista em 2016, foi fruto também da tendência mundial de se discutir a democratização do espaço público da ruas e os novos processos de mobilidade urbana (BASTOS e MELLO, 2017a).

Desse modo, quando em 28 de junho de 2015, a Paulista foi fechada para a inauguração do primeiro trecho da ciclovia desta Avenida, houve concomitantemente o primeiro teste do que se tornaria a Paulista Aberta, uma vez que, naquele dia a via teve o tráfego de veículos interrompidos por algumas horas (COSTA e SAMPAIO, 2015; BASTOS e MELLO, 2017b; SÁ, GARCIA e ANDRADE, 2017; CORDEIRO, MELLO e BASTOS, 2019; FURTADO e CASTRO, 2019). Ainda em 2015, após o teste, atores da sociedade civil se empenharam por meio de organizações e coletivos para que a Avenida Paulista fosse aberta aos pedestres aos domingos e feriados.

A negociação para tal feito, contudo, foi cercada de embates, se assemelhando ao processo de autorização pelo qual o Programa Ruas de Lazer passou em 1976, quando a Prefeitura de São Paulo já enfrentava críticas a respeito do fechamento das ruas para veículos (SÃO PAULO SÃO, 2018). Os discursos contrários naquela época defendiam que a interrupção do trânsito causaria danos aos motoristas e aos comerciantes das áreas ligadas pelas vias destinadas ao lazer (SÃO PAULO SÃO, 2018). Fato semelhante às discussões a respeito da abertura da Paulista que, num primeiro momento não teve apoio nem mesmo do então Prefeito Haddad que assinaria posteriormente, em 2016, a legitimação do Programa (SÃO PAULO SÃO, 2018; MINHA SAMPA, [2020]).

Além das críticas a respeito da interrupção do tráfego de veículo, os Programas Ruas de Lazer e Ruas Abertas também tiveram em comum a mobilização da sociedade civil em favor de sua legitimidade (NOSSA SÃO PAULO, 2015; SÁ, GARCIA e ANDRADE, 2017; SÃO PAULO SÃO, 2018; MINHA SAMPA, [2020]). Nas Ruas de Lazer a iniciativa parte, como já abordado, da cidadã Dirce Vieira e na Paulista Aberta, as reivindicações vêm dos cidadãos organizados em coletivos ou movimentos organizacionais. O que demonstra que ambos os Programas foram atravessados pela participação popular que pressionou a Prefeitura de São Paulo nas duas ocasiões em favor do uso das ruas para a convivência e o lazer (MELLO, BASTOS e LACERDA, 2020).

O processo de mobilização em favor da abertura da Paulista foi tamanho que, além da pressão que vinha sendo realizada online, liderada pelo movimento SampaPé com a apoio dos grupos Bike Anjo, Cidade Ativa, Mobilize, Virada Sustentável, Banco com Encosto, 
Acupuntura Urbana, Conexão Cultural, Bike Café, Ping Point, entre outros, passou também a acontecer mobilizações presencialmente aos domingos em uma calçada da Avenida Paulista, na qual atividades lúdicas eram desenvolvidas com o intuito de divulgar a proposta das Ruas Abertas e reivindicar o uso da Paulista para todos os cidadãos e não só para aqueles que possuíam automóveis (MINHA SAMPA, [2020]).

Outra semelhança encontrada nas Ruas de Lazer e Ruas Abertas está no argumento central defendido pelos Programas que, reivindicam o uso da rua, principalmente para atividades de lazer (SÁ, GARCIA e ANDRADE, 2017; PIMENTEL e CARRANZA, 2020; RETT e BEZERRA, 2019; PEREIRA, RETT e BEZERRA, 2020). Contudo, cabe salientar que o Programa Ruas Abertas parece ampliar tal argumento, adotando o discurso de que as vias como a Paulista, deveriam ser apropriadas pelo maior número de pessoas, sem especificar as formas de usufruto das mesmas (BASTOS; MELLO, 2017a).

Já a respeito das diferenças entre os Programas, o que chama atenção na revisão bibliográfica é a forma como ocorrem as atividades e ações nas ruas e, também o alcance das mesmas. Isto é, se nas Ruas de Lazer a organização e planejamento das atividades é feita por meio do conselho de moradores das mesmas (MEKARI, 2014), que planejam e buscam atender as demandas dos demais residentes da via. No caso das Ruas Abertas as ações são variadas e simultâneas, misturando desde apresentações musicais de artistas, até aulas de dança ao ar livre promovidas por academias de ginástica ou professores autônomos (LEME, 2017).

Outra distinção é referente ao público. Enquanto nas Ruas de Lazer, os frequentadores são, em sua maioria, do próprio bairro (COSTA e SAMPAIO, 2015; SÁ, GARCIA e ANDRADE, 2017), nas Ruas Abertas, especificamente, na Paulista, o público é variado, atraindo inclusive um alto número de turistas (PASSARELLI, 2018; SABINO e PAIM, 2020). Tais diferenciações apontam que a abertura da Paulista, assim como todo o Programa Ruas Abertas, "não conta com nenhuma política e organização que planeje os usos e a programação da Paulista Aberta, que se dá de forma espontânea a partir de atores privados" (SABINO e PAIM, 2020, on-line).

Em decorrência disso, a Paulista Aberta, atualmente, é reduto de diferentes manifestações culturais, atividades recreativas e de lazer e serviços, como:

[...] apresentações de bandas e artistas solo, academias promovendo eventos de ginástica, encontros de religiões diversas, gente fazendo hipnose, a tradicional feira de antiguidades do vão do MASP, a feira na frente do Trianon, shows no palco do vão da FIESP e muitos, muitos ambulantes vendendo de gravuras enquadradas a esculturas de metal, de livros usados a roupas penduradas em araras, de café a corote (PASSARELLI, 2018, on-line). 
Tamanha a diversidade que para Lemes (2017), ainda que esta avenida seja um dos principais centros financeiros da capital paulista, a mesma ganha aos domingos e/ou feriados ares de "parque no asfalto", se assemelhando, dentro das devidas proporções, aos calçadões de Barcelona. O que também não agrada a todos, havendo críticas, especialmente, em relação às bandas ou artistas musicais que se apresentam na via, disputando entre si, cada vez mais, o espaço e a altura do som (PASSARELLI, 2018). Além disso, o argumento contrário ao Programa, desde o início baseia-se no discurso da eficiência e da liberdade de ir e vir (MELLO, BASTOS e LACERDA, 2020).

A partir das circunstâncias apresentadas e após cinco anos de existência do Programa Ruas Abertas, compreende-se que o uso da Paulista no presente está para, além das atividades de lazer, tendo a vida se tornado oportuna para trabalhadores formais e informais comercializarem seus produtos e/ou serviços (LEME, 2017). Por isso, para Bastos e Mello (2017a) a Avenida Paulista está em constante ressignificação que, posterior à sua abertura têm representado uma nova forma de pensar e se apropriar democraticamente a cidade de São Paulo. Esses autores ainda entendem que existem diversas implicações sobre tal uso democrático da Paulista, principalmente quando se leva em conta a mobilidade para se chegar até a via e o público que possui condições socioeconômicas de acessar à mesma. Todavia, para eles a Paulista Aberta significa uma nova possibilidade para que,

[...] a Avenida Paulista se torne um espaço de lugar (de convívio, performatividade, permanência, sociabilidade) e não de fluxos (de circulação de corpos e materiais apenas). Visão que representa um retorno à ideia de apropriação do espaço público, que é uma resposta aos espaços públicos esvaziados atuais, com suas vias servindo apenas aos automóveis (BASTOS e MELLO, 2017b, p. 58).

Portanto, a abertura da Paulista, além de ser fruto do exercício da cidadania, no qual os sujeitos se envolveram na esfera política e conquistaram de forma coletiva suas reivindicações, também parece ser uma nova forma de ressignificar aquele espaço; seja por resgatar a função social da rua como um lugar de encontro para toda a população (MELLO, BASTOS e LACERDA, 2020), ou mesmo por permitir que o cidadão se aproprie da rua de acordo com seu interesse - como no caso daqueles que têm utilizado a Paulista Aberta para comercializar seus produtos e/ou serviços. 


\section{Algumas considerações}

O histórico das Ruas de Lazer na cidade de São Paulo demonstrou que a iniciativa de criação das mesmas já em 1976, nasce da reivindicação pela ocupação do espaço público das ruas pelos cidadãos e, não somente por veículos. Fato que também foi identificado nos discursos acerca da Paulista Aberta entre 2015 e 2016. Além disso, o argumento central em favor de ambos os Programas (Ruas de Lazer e Ruas Abertas) reside no discurso de apropriação das ruas pelos pedestres para a prática de lazer, ainda que nas Ruas Abertas essa noção tenha se ampliado, possibilitando o uso da via para outros fins, como trabalho, por exemplo.

Os embates que cercaram a abertura das ruas para o Lazer em 1976, também é outro ponto em comum entre os Programas, sendo as críticas no presente, inclusive, similares às da década de 1970. A saber, aqueles que se opuseram à abertura da Paulista em 2015, reivindicaram que a interrupção do trânsito era prejudicial aos motoristas e comerciantes da região, mesma afirmação feita pelos críticos das Ruas de Lazer no passado.

Diferentemente das Ruas de Lazer, a Paulista Aberta não possui nenhuma política organizacional que planeje as atividades que lá ocorrem, sendo por isso apropriada das mais diferentes formas pelos cidadãos, atraindo diferentes perfis de visitantes e se caracterizando como importante atrativo turístico da cidade de São Paulo. Por conta disso, há um alto fluxo de pessoas frequentam a via aos domingos e feriados, oportunizando que artistas e comerciantes dos mais variados nichos utilizem a avenida como local de trabalho.

Ao final, reconhece-se o desejo, em ambos os Programas, de que a rua seja um local de encontro destinado para todos os cidadãos. E por isso, ao propor, no início deste artigo, apontar de que forma os traçados históricos das Ruas de Lazer existentes em São Paulo desde 1976, compuseram a mobilização acerca da Paulista Aberta, compreendeu-se que a abertura da Paulista foi fruto, assim como as Ruas de Lazer, do exercício da cidadania aliado às tendências relacionadas à urbanização e mobilidade urbana.

\section{Referências bibliográficas}

BASTOS, A. F. S.; MELLO, S. C. B. Paulista aberta: significados da avenida símbolo da cidade de São Paulo. URBANA: Revista Eletrônica Do Centro Interdisciplinar De Estudos Sobre a Cidade, v. $9, \quad$ n. 3, p. 521-539, 2017a. Disponível em: https://periodicos.sbu.unicamp.br/ojs/index.php/urbana/article/view/8649610. Acesso em 23 de outubro de 2020.

BASTOS, A.F.S., e MELLO, S.C.B. Criando Espaços de Lazer: As Lutas Políticas pela Ressignificação da Avenida Paulista. PODIUM Sport, Leisure and Tourism Review 6(1) 
Janeiro/Abril. 2017b. Disponível em: https://www.researchgate.net /publication/316868037_Criando_Espacos_de_Lazer_As_Lutas_Politicas_pela_Ressignificac ao_da_Avenida_Paulista. Acesso em: 23 de outubro de 2020.

CORDEIRO, A. T., MELLO, S. C. B., e BASTOS, A. F. S. Aqui é a nossa praia! Apropriação e uso da avenida paulista no contexto de políticas de desenvolvimento urbano. urbe. Revista Brasileira de Gestão Urbana, 11, 2019. Disponível em: https://doi.org/10.1590/21753369.011.e20180104. Acesso em 23 de outubro de 2020.

COSTA, A.Q, e SAMPAIO, C.M. Programa Ruas de Lazer da Prefeitura de São Paulo: Modernização na Gestão Pública do Esporte e Lazer. PODIUM Sport, Leisure and Tourism Review. 4(2), Maio/Agosto, 2015. Disponível em: https://periodicos.uninove.br/podium/article/view/9301. Acesso em: 20 de outubro de 2020. FURTADO, M.B, e CASTRO, L.G.R. Espaços de permanência na Avenida Paulista: um recorte de 2016 a 2018. XV Jornada de Iniciação Científica e IX Mostra de Iniciação Tecnológica - INSS 2526-4699 (2019). Universidade Presbiteriana Mackenzie, 2019. Disponível em: http://eventoscopq.mackenzie.br/index .php/jornada/xvjornada/paper /view/1375. Acesso em: 23 de outubro de 2020.

GONÇALVEZ. L. F. O estudo do lugar sob o enfoque da geografia humanística: um lugar chamado avenida paulista. 2010. 266 f. Dissertação (Mestrado em Geografia Humana), FFLCH/USP, São Paulo, 2010.

LABMOB. Avaliação de impacto da Paulista Aberta na vitalidade urbana: relatório técnico. São Paulo, 2018. Disponível em: http://www.labmob.prourb.fau.ufrj.br/wpcontent/uploads/2019/06/Relatorio_Avalia\%C3\%A7\%C3\%A3o-Impacto-Paulista-AbertaVitalidade-Urbana_100_3005.pdf. Acesso em 25 de outubro de 2020.

LEME, A. Avenida Paulista aos domingos vira calçadão democrático. 2017. In: Veja São Paulo. Disponível em: https://vejasp.abril.com.br/cidades/capa-avenida-paulista-passeio/. Acesso em 25 de outubro de 2020.

LOBATO, D. Periferia da cidade tem mais ruas destinadas ao lazer do que o centro. In: 32xSP. 2017. Disponível em:https://32xsp.org.br/2017/05/10/periferia-da-cidade-tem-mais-ruasdestinadas-ao-lazer-que-o-centro/. Acesso em 25 de outubro de 2020.

MACHADO, D.S.C. Av. Paulista: da elite ao povo: as transformações e caracterizações da apropriação do espaço. $211 \mathrm{f}$. Tese (Doutorado em Arquitetura e Urbanismo) - Universidade Presbiteriana Mackenzie, São Paulo, 2014. Disponível em: http://tede.mackenzie.br/jspui/handle/tede/487. Acesso em: 23 de outubro de 2020.

MEKARI, D. Ruas de Lazer: liberdade e autonomia para as crianças. Portal Aprendiz UOL. 2014. Disponível em: https://portal.aprendiz.uol.com.br/2014/04/10/ruas-de-lazer-liberdade-eautonomia-para-as-criancas/. Acesso em: 25 de outubro de 2020.

MELLO, BASTOS e LACERDA. Lutas urbanas no cais Mauá e na Avenida Paulista: metodologia qualitativa para compreensão de transformações no espaço público das cidades. Revista Movimentos Sociais e Dinâmicas Espaciais, Recife, Volume 9, 2020 (106-124). ISSN 2238-8052.

MINHA SAMPA. Paulista Aberta: por uma São Paulo mais Humana. São Paulo, 2015. Disponível em: https://www.paulistaaberta.minhasampa.org.br/. Acesso: 25/10/2020.

MUNHOZ V.C.C. Rua de lazer. In: Gomes C.L., editor. (Org). Dicionário crítico do lazer. Belo Horizonte: Autêntica; 2004. p. 203---6.

NOSSA SÃO PAULO. Avenida Paulista para as pessoas: uma demanda da sociedade civil. 2015. Disponível em: http://www.nossasaopaulo.org.br/noticias/ avenida-paulista-parapessoas-uma-demanda-da-sociedade-civil. Acesso em 23 de outubro de 2020.

OLIVEIRA, M. A. N. Avenida Paulista: a produção contemporânea de uma paisagem de poder. 1998. 296 f. Dissertação (Mestrado em Antropologia) - UNICAMP, São Paulo, 1998. 
PASSARELLI, G. Domingo na Paulista: como o projeto Ruas Abertas mudou a cara da avenida. 2018. In: 360 meridianos. Disponível em: <https://www.360meridianos.com/dica/domingo-na-paulista>. Acesso: 25 de outubro de 2020. PENINA, M. Programa "Ruas de Lazer" é reformulado para incentivar ocupação do espaço público. 2020. In: Catraca Livre. Disponível em: https://catracalivre.com.br/ catraquinha/programa-ruas-de-lazer-e-reformulado-para-incentivar-ocupacao-do-espacopublico/. Acesso em: 25 de outubro de 2020.

PEREIRA, S.L.; RETT, L., e BEZERRA, P. M. Música e dinâmicas dos espaços (semi) públicos em São Paulo: uma análise do evento Paulista Aberta. Trabalho apresentado no XXIX Encontro Anual da Compós, Universidade Federal de Mato Grosso do Sul, Campo Grande - MS. 2020. Disponível em: http://www.compos.org.br/biblioteca/trabalhos_arquivo_ WQUQEY3MJT3YXO4ANM P7_30_8590_02_03_2020_13_13_05.pdf. Acesso em 23 de outubro de 2020.

PIMENTEL, B.L.E., e CARRANZA, E.G. Uma discussão sobre transformações recentes da Avenida Paulista. Revista 5\% Arquitetura + Arte, ano 15,01(19)1-16, jan./jun., 2020. Disponível em: http://revista5.arquitetonica.com/ojs/index.php/ revista5/article/view/133. Acesso em: 23 de outubro de 2020.

RETT, L., e BEZERRA, P.M. Paulista Aberta e Arte Pública: Sobre Derivas e Territorialidades no Espaço Urbano. Trabalho apresentado no $\mathbf{4 2}^{\circ}$ Congresso Brasileiro de Ciências da Comunicação - Belém-PA. 2019. Disponível em: https://portalintercom.org.br/anais/ nacional2019/resumos/R14-0742-1.pdf. Acesso em 20 de outubro de 2020.

Um reconhecimento aos ilustres Mestres da Educação Física. Revista Educação Física. V.10, dezembro, 2003. Disponível em: https://www.confef.org.br /confef/comunicacao/revistaedf/3499. Acesso em: 20 de outubro de 2020

ROSA, M.C.; FERREIRA, J. T. A. Ruas de recreio na cidade de Belo Horizonte (fim da década de 1950 até 1980). Rev. Bras. Ciênc. Esporte, Porto Alegre , v. 41, n. 4, p. 451457, Oct. 2019 . Disponível em: <http://www.scielo.br/scielo.php?script= sci_arttext\&pid=S0101-32892019000400451\&lng=en\&nrm=iso>. Acesso: $25 / 10 / 2020$.

SÃO PAULO SÃO. "Ruas de Lazer": nos anos 70, brincadeira era na rua e aos domingos. 2018. Disponível em: https://saopaulosao.com.br/nossos-encontros/742-ruas-de-lazer-nosanos-70,-brincadeira-era-na-rua-e-aos-domingos.html\#. Acesso: 25 de outubro de 2020.

SABINO, L. e PAIM, C. Abrir ruas para as pessoas estimula o comércio e ativa as fachadas. In: Caos Planejado. 2020. Disponível em: https://caosplanejado.com/abrir-ruas-para-aspessoas-estimula-o-comercio-e-ativa-as-fachadas/. Acesso em 28 de outubro de 2020.

SÁ, T.H.; GARCIA, L.M.T., e ANDRADE, D.R. Reflexões sobre os benefícios da integração dos programas Ruas de Lazer e Ciclofaixas de Lazer em São Paulo. Revista Brasileira de Atividade Física \& Saúde; 22(1)5-12, 2017. Disponível em: https://rbafs.org.br/RBAFS/article/view/7767. Acesso em 20 de outubro de 2020.

SANTOS JÚNIO, S.A. Ruas de Eventos: Práticas de lazer em três momentos históricos da cidade de São Paulo. 177f. Dissertação (Mestrado em Arquitetura e Urbanismo) Universidade Presbiteriana Mackenzie, São Paulo, 2016. Disponível em: http://tede.mackenzie.br/jspui/handle/tede/2913. Acesso em 23 de outubro de 2020.

SÃO PAULO. Decreto n ${ }^{\circ}$. 55.684 de 12 de novembro de 2014. Confere nova regulamentação à Lei $\mathrm{n}^{\circ} .12 .264$ de 11 de dezembro de 1996, dispõe sobre a implantação de áreas de lazer em vias públicas no perímetro urbano da capital e dá outras providências. 2014. Diário Oficial do Município de São Paulo, 13 de novembro, 2014. Disponível em: http://legislacao.prefeitura.sp.gov.br/leis/decreto-55684-de-12-de-novembro-de-2014. Acesso em 26 de novembro de 2020. 
STOPPA, E. A., et al. Gestão de Esporte e Lazer: análise dos espaços e equipamentos de esporte recreativo e de lazer em Ermelino Matarazzo, Zona Leste de São Paulo. São Paulo: Plêiade; 2011. 